\title{
BENITO PÉREZ GALDÓS Y VICTORIANO SALADO ÁLVAREZ: SU VÍNCULO A PARTIR DE DOS RELATOS CORTOS
}

\author{
Diego Mejía Estévez \\ Universidad Nacional Autónoma de México \\ diego.mejia.estevez@gmail.com
}

Resumen: Este artículo aborda las relaciones entre Benito Pérez Galdós y Victoriano Salado Álvarez mediante el comentario de dos cuentos aparecidos en prensa. Ambos relatos breves se vinculan con las preocupaciones estéticas que circulan en las últimas décadas del siglo XIX, precisamente en el conflictivo entrecruce de la práctica realista con otras corrientes como el modernismo, el naturalismo, el folletín y, significativamente, las mutaciones que se producen debido al auge del periódico como medio masivo de difusión de la literatura. Asimismo, se reflexiona sobre los matices de la representación del artista en el marco de dichas poéticas y movimientos.

Palabras clave: realismo, relato corto, bohemia, Victoriano Salado Álvarez, Benito Pérez Galdós.

\section{BENITO PÉREZ GALDÓS AND VICTORIANO SALADO ÁlVAREZ: THEIR CONNECTION BASED ON TWO SHORT STORIES}

\begin{abstract}
This paper deals with the texts of Benito Pérez Galdós and Victoriano Salado Álvarez by means of a commentary on two stories printed in press. Both short stories are connected by the aesthetic concerns that appeared in the last part of the $19^{\text {th }}$ century. It was precisely in the conflict between the realism and the modernism, naturalism, the feuilleton, and mainly, the changes that were produced by the boom of press as massive media. In addition, it reflects on the many representations of the artist on the frame of the poetics and diverse cultural movements.
\end{abstract}

Keywords: realism, short story, bohemianism, Victoriano Salado Álvarez, Benito Pérez Galdós.

DOI: https://doi.org/10.24029/lejana.2022.15.3559

Recibido: el 15 de septiembre de 2021

Aceptado: el 15 de diciembre de 2021

Publicado: el 25 de febrero de 2022 
Con este artículo deseo explorar los vínculos que existen entre dos grandes escritores que las historias literarias consideran adscritos al realismo. Quizá la divergencia que salta primero a la vista es la honda discordancia entre sus fortunas editoriales. Benito Pérez Galdós es la figura tutelar de la poética realista de las letras hispánicas, y se ha intentado llevarlo — me parece que con acierto y justicia - al restricto círculo del canon europeo decimonónico, como es perceptible en trabajos como el de Germán Gullón, Galdós, maestro de las letras modernas (2020). Por otra parte, aunque Victoriano Salado Álvarez fue un escritor muy respetado en su tiempo, con textos encomiados por figuras como Amado Nervo, terminó por caer en un profundo olvido - interrumpido, acaso, por las valoraciones que José Emilio Pacheco le dedica en su compilación La novela histórica y de folletín (1985), así como en diversas intervenciones en prensa - hasta que el Instituto de Investigaciones Filológicas de la Universidad Nacional Autónoma de México, de la mano de Alberto Vital y Alejandro Shuttera, emprendió su rescate editorial.

Con este marco, puede intuirse que las relaciones entre ambos escritores realistas poseen un orden jerárquico en que el autor español lleva la mejor parte, en especial cuando se piensa que el mexicano rindió tributo a Galdós al construir sus Episodios nacionales mexicanos (1902-1906) a semejanza del casi homónimo ciclo de novelas históricas galdosianas. Buena parte de la convergencia entre Galdós y Salado ha sido comentada por Vital y Shuttera, en especial por el último en el estudio preliminar a Obras III. Episodios nacionales mexicanos, I. De Santa Anna a la Reforma, 1 (2018), así como por María Guadalupe Sánchez Robles, aunque casi siempre a propósito del nexo entre los monumentales ciclos de novelas que cada quien realizó. En cambio aquí me concentro, fundamentalmente, en dos relatos mucho menos atendidos por la crítica: "Un tribunal literario" (1873), de Galdós, y "De la vida de bohemia" (1922), de Salado, una elección que permite ver la ligazón desde otras aristas. Al asociar este par de relatos breves, también discurro sobre algunos aspectos de la mixtura que ejercen estos autores de distintos géneros y formatos, a saber, la novelística, la narrativa y el periodismo.

\section{Pérez Galdós admirado por Salado Álvarez}

Como sugiero líneas atrás, hay una evidente impronta galdosiana en el autor mexicano, que inicia con la génesis del ciclo novelístico Episodios nacionales mexicanos, escrito por encargo del editor catalán Santiago Ballescá, "a quien la literatura y, en general, la cultura mexicana le deben mucho más de lo que han querido agradecerle" (Vital, 2002: 134), ya que a él se debe no solo la encomienda y publicación de las series de Salado sino la edición de obras insoslayables como $E l$ Zarco (1901) de Ignacio Manuel Altamirano, o la enciclopedia México a través de los siglos (1884), dirigida por Vicente Riva Palacio.

Es, hasta cierto punto, curioso que Ballescá encargue al autor mexicano - originario de Jalisco- este proyecto, pues no cuenta con novela alguna en su haber. Lo que sí tiene es un libro de cuentos, De autos (1901), y un profundo interés por la historia de México basado en un humanismo de raíz comtiana. Vital sintetiza del siguiente modo las importantes particularidades que hay en la lectura saladiana del filósofo francés: "Y es que puede deducirse que, desde la 
perspectiva de Comte, quien además menciona como lectura altamente deseable nueve novelas del progenitor reconocido de la novela histórica, Walter Scott, este género podía ser la síntesis perfecta de tres disciplinas que, en su convergencia, daban curso a un peculiar humanismo práctico" (2002: 133). Es entonces que Salado, bajo este esquema, puede trenzar sus intereses históricos y estéticos. Asimismo, puede verse que su concepción de la novela histórica se asocia al modelo de Scott que Balzac adopta, refina y populariza en su propio ciclo. Como explica Guido Mazzoni: "En torno a 1830, las reflexiones de Balzac sobre Scott se transforman en un principio de poética [...]. Desde ese momento en adelante, para Balzac, Walter Scott se vuelve el modelo técnico que todos los novelistas contemporáneos deberían seguir y la forma teatral se torna el elemento arquitectónico decisivo de la Comédie humaine" (Mazzoni, 2011: 254-255). ${ }^{1}$ Entre esos novelistas contemporáneos puede contarse, al menos, a los practicantes del realismo. Empero, además del influjo de Scott y Balzac, Galdós se vuelve modelo directo para Salado no solo por practicar ese mismo método, sino a causa de una voluntad de filiación con la tradición hispánica que encarna el narrador canario, y que obedece a tensiones que más tarde comentaré.

En todo caso, "Salado Álvarez se propone reproducir el modelo galdosiano porque le parece la herramienta más efectiva para dar lugar a un efecto semejante al que cree ver en el intertexto enfocado: es decir, el recuento histórico preciso y objetivo, y además, la oportunidad de que su narración se consolide como un documento de promoción de la información recabada, esto es, lo histórico" (Sánchez Robles, 2021: 35-36). La pretensión de un efecto de realidad y una objetividad de la narración que intenta emular la figura del historiador son, en este caso, un sello del estilo saladiano provocado por Galdós, por lo demás visible en los Episodios.

Bastante tiempo después de esta aventura novelística, Salado tuvo la oportunidad de conocer a su modelo e ídolo literario, y deja testimonio de ello en una crónica que publica en $L a$ Prensa de San Antonio:

Le hablé luego de su aparición como periodista, de su "Audaz", de "La Fontana de Oro", de las Porreñas de Vozmediano, de aquella pintura del Madrid viejo que vence a la del "Curioso Parlante" aunque esté en ella inspirada, de las portentosas series de los "Episodios Nacionales" en que hay figuras dignas de un Balzac y de un Dickens a un tiempo: el Príncipe de la Paz, el Tío Cura, Amaranta, la Monja Apóstata de "Un Voluntario Realista", Cordero, don Felicísimo Carnicero. Y sobre todo los dos personajes principales que cada uno a su manera simbolizan la España heroica del tiempo del Emperador y de Álvarez de Castro, la España cazurra y levítica de la Restauración: Gabrielillo Araceli y Juan de Pipaón. (Salado Álvarez, 1922: 10)

Resalta allí la asociación con los maestros del realismo, además de que asienta constancia sobre el conocimiento profundo que Salado tiene de la obra galdosiana y los méritos que le reconoce, sobre todo en cuanto a su capacidad de retratar un tiempo histórico.

\footnotetext{
${ }^{1}$ En el original en italiano, cuya traducción el español es mía: "Intorno al 1830, le riflessioni di Balzac su Scott si trasformano in un principio di poetica [...]. Da quel momento in poi, per Balzac, Walter Scott diviene il modello tecnico che tutti i romanzieri contemporanei dovrebbero seguire e la forma teatrale diviene l'elemento architettonico decisivo della Comédie humaine".
} 


\section{El Galdós de "Un tribunal literario"}

Tanto Galdós como Salado fueron incansables escritores de prensa, y a sus monumentales novelas, series y ciclos se añade una interesante y paralela producción cuentística que hace, a veces, espejo y correlato a sus otros proyectos; en otras ocasiones, el cuento se vuelve un espacio en que les fue posible experimentar mecanismos e intereses sumamente distintos, como es el caso del registro fantástico, con cuentos como "La conjuración de las palabras" (1868) o "Rompecabezas" 1897, en el caso del autor canario. Acerca de la faceta del cuento, debe tenerse en cuenta la opinión de Yolanda Arencibia:

Al abordar la producción breve de Galdós era habitual, casi hasta ahora mismo, lanzar a modo de queja la afirmación de que "se han estudiado poco los cuentos de Galdós". Eso ya no es cierto; aunque es obvio, sin embargo que, tratándose de Galdós, cualquier vertiente de su genio (el dramaturgo, el narrador de cuentos, el periodista...) está menos estudiada que sus creaciones novelísticas. (2015: 110)

Lleva mucha razón Arencibia. Y con todo, el mismo nexo entre Galdós y Salado ha sido comentado únicamente a propósito de su faceta novelística. En el marco de ese laboratorio que fueron muchas veces los cuentos para ambos escritores, es posible rastrear otras convergencias, como fue por ejemplo la jerarquía que tanto los medios como los autores designaron a su práctica de los distintos géneros:

Así como fue costumbre entre los escritores a caballo entre los siglos XIX y XX, también la producción galdosiana de narrativa breve acompaña de manera constante la publicación de las novelas, las de la Primera época y buena parte de las Españolas contemporáneas, como vehículo paralelo al gran "empeño" de la escritura realista/naturalista, con su propio canal editorial representado por la prensa periódica, a su vez con su variado y amplio público de lectores. Sin embargo, para Galdós, a menudo el espacio contraído del relato, su ritmo en la narración marcando con rigor los necesarios movimientos en la aparición de los personajes, así como de cada elemento informativo que luego cobrará sentido, ofrecen un adecuado cobijo a sus reflexiones metaliterarias. Esta praxis fictivo-ensayística, si se me permite el término en cierto sentido oximórico, se realiza proficuamente en el cuento gracias al tono decididamente más irónico que Galdós elige, además de la dimensión fantástica en la cual a menudo los sumerge. (Polizzi, 2019: 202)

En el caso del cuento "Un tribunal literario" no opera ese ámbito fantástico que menciona Polizzi, pero sí el tono irónico y, especialmente, la reflexión metaliteraria a propósito de la eclosión de poéticas varias que proliferan en el arte narrativo de la segunda mitad del siglo XIX.

Dicho cuento, publicado en Revista de España en 1872, se abre con un diálogo entre el duque de Cantarranas - un autor ficticio que encarna una suerte de romanticismo sentimental—y un joven que trabaja en la confección de una novela, y que ha congregado a doctas autoridades de la crítica literaria para que juzguen su trabajo y esclarezcan cuál puede ser el mejor rumbo para su obra, precisamente en ese agitado cruce de corrientes literarias que pauta las prácticas narrativas de la época.

Sin duda, se trata esta de una preocupación que atañe al mismo Galdós, quien habita más o menos el mismo escenario que su personaje y está luchando por consolidar un arte literario propio entre tantos ismos. Además de las distintas poéticas, el escritor está en el vaivén de al menos dos intereses ligados a su primera y a su segunda manera, implícitos cuando Gullón menciona: 
Hay, al menos, dos Galdoses. El que desde la juventud se interesa por los problemas de la sociedad en que habita, reflejándola en sus páginas, revisando su historia, los problemas causados por las diferencias económicas, de educación, de físico, de inteligencia, y el escritor maduro. Este hombre se preocupará por la persona concreta, por entender lo que la mueve por dentro. Volveremos luego sobre el asunto, de momento digamos que la madurez personal le llevó a fijarse mejor en los sentimientos concretos de quienes vivían a su alrededor. (2014: sp)

El Galdós, pues, del cuento en cuestión está inclinado hacia los conflictos de su contemporaneidad, que son aquí de índole estética. En cambio, está aún muy lejos de ese estudio de la interioridad y la mentalidad de los individuos que se ensaya, por ejemplo, en La desheredada (1881). La narración concede un relevante espacio a la descripción física de los personajes que constituyen el tribunal y a los recursos que consideran más eficaces al oficio narrativo. Empero, salvo algunas manías, esa otra dimensión de su ser es del todo desconocida. Con respecto al narrador, y presunto protagonista, se conoce aún menos, y resulta una figura sin personalidad a la manera de la creatura novelesca balzaquiana de Lucien de Rubempré, como detallaré líneas abajo.

Por otro lado, en cuanto al diálogo entre el personaje narrador en ciernes y el duque romántico, a quien considera su benefactor, pone sobre la mesa importantes temas, pues el duque habla sobre la importancia de que el arte narrativo exalte los sentimientos y que conmueva por su fuerza. Asimismo, se traza una antinomia entre este modo de hacer literatura y otro que estaría apegado a la "pasión política". Con esto, se intenta contraponer la poética romántica, o cuando menos una de sus vertientes, con el realismo y sus derivados que miran con mayor acento las tensiones de la vida cotidiana y del presente, como puede ser la dimensión política.

El capítulo segundo se centra en la descripción de una poetisa que es retratada bajo la estructura del tipo, esto con el fin de mostrar una galería de literatos cuyas estampas y opiniones son, en mayor o menor medida, caricaturas de los individuos reales que desfilaban en el mundillo literario de la época. Mientras tanto, la tercera parte presenta a Don Marcos, un novelista devenido crítico a causa de las cuitas económicas que encuentra en la labor artística. Su forma de comprender la literatura se describe así:

D. Marcos huía de las sencillas y puras escenas de la naturaleza; y así como el pez no puede vivir fuera del agua, la Musa susodicha no se encontraba en su centro fuera de las infectas bohardillas, de los húmedos sótanos, de todos los sitios desapacibles y repugnantes. Sus pinturas eran descarnados cuadros, y sus tipos predilectos los más extraños y deformes seres. Un curioso aficionado a la estadística, hizo constar que en una de sus novelas salían veintiocho jorobados, ochenta tuertos, sesenta mujeres de estas que llaman del partido, hasta dos docenas y media de viejos verdes, y otras tantas viejas embaucadoras. Su teatro era la alcantarilla, y un fango espeso y mal oliente cubría todos sus personajes. Y tal era el temperamento de aquel hombre insigne, que cuanto Dios crió lo veía feo, repugnante y asqueroso. Estos epítetos los encajaba en cada página, ensartados como cuentas de rosario. Era prolijo en las descripciones, deteniéndose más cuando el objeto reproducido estaba lleno de telarañas, habitado por las chinches o colonizado por la ilustre familia de las ratas; y su estilo tenía un desaliño sublime, remedo fiel del desorden de la tempestad. (Pérez Galdós, 2006: 180-181)

Se advierte entonces la representación de un artífice de cuño naturalista, tanto por los personajes que utiliza como por su deleite en la descripción de los más sórdidos estadios, y en cuyos colpi di scena el protagonista parece hallar los resortes y giros que quiere imprimir a su pretendida obra. 
Lo cierto es que la poética que ostenta Marcos parece la más contrapuesta a la concepción hasta ahora referida en el cuento, la del duque y la poetisa de filiaciones románticas y que, incluso, el narrador tilda de cursi. La galería se completa con Severiano Carranza, conocido también como Flavonio Mastodontiano, un erudito que entiende la literatura como una suerte de reconstrucción filológica y evoca además un poco a los neoclásicos.

Sin embargo, Galdós no legitima nunca modelo alguno de poética, aunque quizá fustiga con mayor dureza la visión romántica, como también lo haría en El doctor Centeno (1883) con la narración de los ridículos y febriles proyectos del dramaturgo Alejandro Miquis, y su desastrada bohemia en la que se concentran diversos tópicos de esta como la tuberculosis, la vida galante y la generosidad desmedida incluso en la pobreza.

Más atrás hablé del enigmático protagonista de "Un tribunal literario", quien tendría el punto de vista privilegiado y resulta el único sujeto autónomo de la narración. Sobre el primer asunto, me ciño a la definición de Cesare Segre: "El punto de vista considera el modo de presentar los hechos, en definitiva el ángulo desde el cual se revela cada uno de los eventos que constituyen la trama (2018: 135). En cuanto a lo segundo, coincido en lo siguiente: "Cuando un actante posea su propio programa, sus propias metas, y actúe para lograr su objetivo, será un sujeto autónomo" (Bal, 1990: 40). Sin embargo, a pesar de que el personaje narrador, en sentido doble, posea su programa, este es del todo maleable. Por esa razón, lo asocié al personaje escritor Lucien de Rubempré de Illusions perdues (1837-1843) de Balzac.

El poeta que protagoniza la novela de Balzac es un artífice con talento y sensibilidad, pero sumamente ambicioso y, sobre todo, voluble, y que transita de una poética a otra, de un medio, género literario o bando al siguiente según le convenga. A pesar de su lugar como héroe de la narración, es claro que casi cualquier personaje o moda pueden influenciarlo. Franco Moretti va a describir su naturaleza de la siguiente forma:

Esa misma ductilidad que le permite estar constantemente "al paso de los tiempos" le impide también constituirse como individualidad permanente: lo condena a no poder ser nunca "sí mismo". Tarde o temprano, todos los personajes que le son cercanos descubren que, de Lucien, no pueden fiarse. ¿Por qué es egoísta? Pero sobre todo ya que, en el fondo, Lucien no existe - no existe como persona. Es un ser puramente social, un "hijo de su siglo"-. (Moretti, 1999: 148)

El personaje del cuento galdosiano, tras recabar todos los consejos y propuestas de las autoridades que congrega para escuchar y comentar su relato, no puede decidir qué camino tomar y pasa de una postura poética a otra con la misma ductilidad que el poeta de Balzac.

Asimismo, el texto cierra con una acalorada y cómica discusión entre los escritores del tribunal y con la publicación de la novela, que es definida como "análoga a esas capas tan llenas de remiendos y pegotes, que no se puede saber cuál es el color y la tela primitivos" (Pérez Galdós, 2006: 205), a causa de que el joven novelista mezcla aquí y allá un poco de todas las

\footnotetext{
${ }^{2}$ En el original en italiano, cuya traducción el español es mía: "Ciertamente. Quella stessa duttilità che gli permette di essere costantemente «al passo coi tempi» gli impedisce anche di costituirsi come individualità permanente: lo condanna a non poter essere mai «se stesso». Prima o poi, tutti i personaggi che gli sono vicini scoprono che, di Lucien, non ci si può fidare. Perché è egoista? Certo. Ma ancor piú perché, al fondo, Lucien non esiste - non esiste come persona. Ė un essere puramente sociale, un «figlio del secolo»-".
} 
recomendaciones recibidas. Tales características derivan en que la obra sea vendida, poco después de impresa, como mero papel por peso para satisfacer las necesidades del dueño de una tienda de ultramarinos, utilizando en clave irónica el motivo dominante de las Illusions perdues que es el papel, el cual Balzac presenta en todas sus fases ligadas a la industria de la imprenta, hasta su función más sublime en tanto vehículo de la creación artística de su personaje.

\section{Victoriano Salado y "De la vida de bohemia"}

Como sucedió a Galdós, Salado se formó con la escritura periodística de artículos y cuentos, también mucho menos conocidos y estudiados que el mencionado ciclo. Para comprender mejor tales prácticas deben apuntarse las circunstancias que Vital detalla:

Victoriano tuvo mucho que ver con las condiciones del mercado y del incipiente sistema literario mexicano, sujetos ambos (mercado y sistema) a la fuerte y benéfica influencia del periodismo diario y semanal, quincenal y mensual. A una vocación narrativa natural se aunó en Salado la apertura de espacios editoriales y de ofertas de publicación para las nuevas generaciones de prosistas y poetas tanto románticos como realistas, tanto naturalistas como modernistas. (2012: XXIII)

Esto en lo que respecta a la primera fase del trabajo literario y periodístico del jalisciense, sin embargo, "De la vida bohemia" es publicado ya en 1922 (en El Informador), ${ }^{3}$ es decir, dos décadas después de comenzada la aparición de los Episodios.

En ese cuento, a modo de resumen mínimo, se relatan las cuitas de Rubén Darío y Amado Nervo en su estadía parisina, en particular la noche de Navidad, y las extravagancias de Darío derivadas de sus escarceos báquicos:

No era precisamente trufas lo que se comía ni champaña lo que se cataba hace veinte años en el aposento de dos poetas hispanoamericanos que vivían en París, rue de la Parchéminerie, número 57. De ellos el más joven, Amado Nervo, acababa de llegar a París hacía unos cuantos meses, mientras el otro, Rubén Darío, llevaba ya algún tiempo en la capital de Francia. (Salado Álvarez, 2019: 43)

El asunto del relato tiene que ver con preocupaciones añejas en su autor, asimismo vinculadas a la famosa polémica que sostuvo con los modernistas en 1898, a raíz de su reseña al libro Oro y negro (1897) de Francisco Olaguíbel. Allí, la mayor crítica de Salado es porque considera que muchas de las estrategias modernistas son tan solo un remedo de los postulados —en su opinión mal comprendidos - simbolistas y decadentistas de Francia. La postura del jalisciense tiene que ver con la consolidación del campo de la literatura patria, para cuya concreción considera mucho más benéfica la cercanía con las letras hispánicas. Se entiende así la elección del realismo galdosiano como modelo. Y del mismo modo, como explica Shuttera, "el cultivo de la novela histórica en México no obedece a una «moda literaria» [...]. Es más bien la consecuencia directa de la pregunta por la identidad nacional” (Shuttera, 2018: XXVIII).

\footnotetext{
${ }^{3}$ El cuento se publica originalmente en dicho diario. Aquí cito la versión que se recoge, luego de su actualización ortográfica y de puntuación, en Diálogos de otros tiempos. Narraciones y sucedidos mexicanos por Alejandro Sacbé Shuttera, y que se publica por Penguin en 2020.
} 
Debido a la naturaleza y estilo de este escritor, también filólogo, crítico e historiador acucioso, puede postularse que considere la poética realista una manera escritural que ya ha sido verdaderamente asimilada, a más de medio siglo de publicadas las obras maestras de Balzac y Stendhal, en el contexto de una tradición literaria mexicana apenas en consolidación. En cambio, la recepción y práctica del decadentismo debieron carecer a sus ojos de una distancia crítica, además de responder a tensiones que considera ajenas al entorno estético y social del país. Y, sobre todo, el tipo de narrador omnisciente propio del realismo, con su pretendida cercanía respecto a la figura del historiador por su objetividad, es más deseable para Salado que los narradores volcados en su experiencia íntima y tantas veces despreocupados de su marco social e histórico, cuando no en franca oposición a él.

A esto se añade la estrecha colaboración de Salado con Rafael Reyes Spíndola, fundador del periódico El Universal, cuyas prácticas fueron, en general, consideradas por los modernistas típicas de un "periodismo industrial" que debía combatirse. Por otro lado, está la férrea defensa de una práctica antiutilitarista del arte por parte de los modernistas mexicanos, bajo la devisa de l'art pour l'art, que se atribuye a Théophile Gautier, y que intentaran practicar por esa época autores como Oscar Wilde y Gabriele D'Annunzio, por cierto, admirados por Salado, como se constata en los textos y traducciones que les dedica en los periódicos. ${ }^{4}$

Además de este contexto de pugna contra los modernistas, que comenzó con la reseña y tuvo otras repercusiones que aquí es imposible abordar, lo cierto es que Salado no tenía en el mejor de los conceptos al poeta de Nicaragua, como se revela en una crónica que publica dos años después de su cuento en el mismo periódico y que discurre sobre la misma línea: "En ese tiempo Darío estaba entregado al vicio de la bebida y ejecutaba las cosas más extrañas y asombrosas. Una tarde, en la terraza del «Lion d'Or», empezó a quejarse de que estaba envenenado y a pedir por Dios un confesor como el don Juan de Tirso" (Salado, 1924: 3).

Salado cumple con varios objetivos a través de su relato, a saber, la continuación de su ejercicio narrativo ya lejos de la trayectoria novelística; censurar una imagen del artista que se contrapone a su visión de mundo y que se había vuelto ya un mito literario a partir del poète maudit simbolista que encarnaron Charles Baudelaire o Paul Verlaine - el ídolo de Darío-; y, por último, mofarse de la práctica del género que el vate modernista llamara "cuento parisiense" a propósito de "La ninfa" del célebre volumen Azul (1888). Esto último constituye un ataque directo a la narrativa modernista, por no hablar del embate particular a la figura del máximo representante del movimiento. Por otro lado, el jalisciense, en el marco de la narrativa breve, se ejercita en otro género que les es caro y que viene tan bien al medio de la prensa en que se mueve: el retrato. Como explica Vital:

Y, sin duda, la fascinación de muchos autores y lectores por los personajes públicos está en la base misma de la existencia de la novela histórica y de la novela en clave, ya que la cantidad de energía social acaparada y consumida por esos personajes es tan grande que la comunidad va a buscar las huellas de tal energía histórica en esos y en otros géneros [...].

\footnotetext{
${ }^{4}$ Por ejemplo, Salado Álvarez traduce desde una versión francesa, para el diario Flor de Lis de Guadalajara, Le vergini delle rocce (1895) apenas un año después de su publicación. Asimismo, en 1929 le dedica una semblanza, bastante laudatoria, al artista italiano en La Prensa.
} 
Tal vez por todo lo precedente se explica que el autor de los Episodios nacionales se sintiera siempre tan seguro al hacer un retrato de personas vivas o recién muertas e incluirlo en su texto: porque a la vez era realista, era positivista y era escritor [...]. El retrato fue entonces un punto de confluencia de poderosas corrientes ideológicas y estéticas. (2002: 167)

Se trata este de un procedimiento que Salado ya había practicado en Su Alteza Serenísima (1902), al mostrar los primeros pasos de su héroe, Juan Pérez de la Llana, que se vinculaba al grupo real de La Falange y a escritores como el poeta Juan Covarrubias. En todo caso, la imagen del poeta primero apurado por la mala administración de su pecunio, y luego que dilapida cualquier moneda que llegue a sus manos para procurarse la algarabía del goce dionisiaco, es la base de una historia apasionante que recurre a casi todos los topoi de la bohemia, ya representada literariamente por diversas obras, entre las más famosas Scènes de la vie de bohème (1851) de Henry Murger. La distancia clara con las estampas de Murger es que los personajes, más que jóvenes simpáticos que se diviertan a expensas de la sociedad burguesa, encuadran más, en el caso de Darío durante el cuento saladiano, con una imagen trágica y casi patológica: "empezó a trasegar desde temprano todos los licores de diferente sabor, densidad y coloración que tanía a la vista, y antes de que fuera 'media noche, cuando Dios quiso nacer', ya se encontraba en ese estado de embriaguez trágica, villana y pendenciera que tienen algunos que debieran observar siempre la ley de Volstead" (Salado Álvarez, 2019: 45). El gesto del poeta se muestra, asimismo, como estrafalario y producto de un romanticismo trasnochado, herencia visible en los modernistas y decadentistas bajo la óptica del jalisciense.

Por lo demás, la estadía parisina del personaje Rubén Darío no podría entenderse sin su ejercicio periodístico para La Nación de Argentina. Entonces, ese héroe artista del relato es también un personaje periodista como lo fuera el comentado Lucien de Rubempré, y con esta marca se continúa la reflexión acerca del estrecho nexo entre el ejercicio literario y el periodístico, pero también sobre la imperiosa necesidad que tenían la mayoría de los artistas por desarrollar otras actividades mejor, o más asiduamente, remuneradas. Se trata este de un drama que vivió el mismo Salado, quien debió hacer del periodismo su fuente primaria de sustento - especialmente durante su exilio en Estados Unidos - en detrimento de otras actividades y proyectos creativos.

\section{Conclusiones}

El paso de Salado por la prensa, además de ser producto de las condiciones de mercado que comenta Vital, y de sus necesidades personales, tiene una función similar a la de Galdós en sus consabidos esfuerzos por triunfar en el arte de Molière y Shakespeare. Más que la novela, "en cambio, el cuento, el sucedido, el diálogo y la escena son cuatro géneros que avinieron bien a su triple urgencia de 1) escribir, 2) mantener a una familia y 3) comunicar sus ideas, sus inquietudes y sus historias a un público más o menos amplio" (Vital, 2021: 158). Hablo en particular de esa voluntad de establecer un diálogo con la gente lectora a un nivel masificado. Esto puede parecer, hasta cierto punto, paradójico, pues, aunque la novela era un género de enorme hegemonía y difusión, la prensa, merced a las transformaciones mencionadas, incluso rebasa la penetración de la novelística. Salado tiene cierta aversión por la mixtura de novela y periódico que en otros 
novelistas funciona tan bien, y al contrario considera las formas breves como una simbiosis perfecta con el médium de la prensa. Además de que mezclar el trabajo periodístico, relativo a los diversos artículos de orden histórico, filológico, lingüístico y político que escribe, con la confección de cuentos sea pertinente para el mexicano, cabe decir también que esta ocupación de periodista y su carrera política no le conceden las fuerzas necesarias, o el tiempo, para acometer de nuevo un ejercicio en la forma novela, y en especial de las magnitudes que practicara con sus Episodios nacionales mexicanos. Del mismo modo, "en camino de animarse a escribir sus memorias Victoriano había vislumbrado las anécdotas del medio literario como un rico filón que podía resultar atractivo para el público. La rememoración del campo literario del Porfiriato fue uno de los tópicos más atendidos" (Viveros, 2021: 166).

Pero, más allá de la convergencia que hay en abordar los asuntos actuales, en este caso estéticos, por parte de ambos autores realistas, es de gran relieve que en estos cuentos se concentren en desacralizar la figura del artista literario mediante el humor y la ironía que le falta a Balzac para trazar a su poeta romántico en Illusions perdues, aun cuando este tenga tantas coincidencias con los personajes a caballo entre ficción y realidad de Galdós y Salado.

Entonces, se trata de una situación compleja y llena de matices, pues el escritor jalisciense no desestima ni desconoce la poética decadentista, pero desconfía de la asimilación y utilización de los escritores mexicanos. Además, ciertamente, el enfrentamiento de los modernistas con Salado va en sintonía con los ataques de Ramón María del Valle-Inclán, autoridad del decadentismo español, con el consabido mote de "garbancero" que da a Galdós. En suma, hay también una desconfianza sistemática de los modernistas o decadentistas hacia una poética que consideran rebasada, y de ahí el repudio a sus autores representativos en España y México.

No hay, en realidad, una exhibición vistosa de las estrategias típicas del realismo en ninguno de los relatos aquí abordados; no abren con una descripción detallada del marco histórico y social a la manera de inicios paradigmáticos como los de I promessi sposi (1827) de Alessandro Manzoni o Le Père Goriot (1834) de Balzac. Además de que un uso de la diégesis para una construcción minuciosa de las "dos teletas teatrales: una compuesta de entidades invisibles, de fuerzas históricas, sociales, psicológicas, económicas; otra compuesta de entidades visibles, de objetos, de ambientes" (Mazzoni, 2011: 258) $)^{5}$ es más o menos incompatible con el formato cuento, tampoco se utiliza un registro melodramático propicio a los giros y reconocimientos balzaquianos.

Más bien, opera una adhesión indirecta al realismo mediante una reflexión metaliteraria y una toma de postura que es, esencialmente, crítica. En el caso de "Un tribunal literario" es ostensible en el rechazo, y hasta ridiculización, de los tópicos del Romanticismo, y en menor medida a los excesos del naturalismo. No hay, pues, una declaración de un método narrativo ideal para confeccionar la novela del protagonista sino por omisión; la preocupación característica de la poética realista por las fuerzas históricas que ejercen una influencia directa en los destinos de los personajes no solo no afectan a los escritores ficcionales del relato, sino que tampoco les importan como materia narrable a añadirse en la novela en ciernes en que el cuento se centra.

\footnotetext{
${ }^{5}$ En el original en italiano, cuya traducción el español es mía: "due quinte teatrali: una composta di entità invisibili, di forze storiche, sociali, psicologiche, economiche; un'altra composta di entità visibili, di oggetti, di ambienti".
} 
Ocurre algo parecido con "De la vida de bohemia", que tampoco hace gala particular de elementos realistas, pero su crítica a aquellos modernistas se entiende perfectamente al ser interpretada en relación al corpus general del autor; con sus novelas realistas de carácter histórico y fuerte impronta galdosiana, además de sus diálogos con Nervo y compañía en la prensa. La confluencia e influencia es más bien visible en las intenciones de ambos autores que buscan defender la práctica del realismo en la segunda mitad del siglo XIX e, incluso, en los albores del siglo XX.

\section{Bibliografía}

ARENCIBIA, Yolanda (2015): "Fundamentos de Galdós. Los cuentos". Actas del x Congreso Internacional de Estudios Galdosianos (2015): 110-118.

BAL, Mieke (1990): Teoría de la narrativa. Una introducción a la narratología. Madrid, Cátedra. Gullón, Germán (2014): "Introducción. Tristana, la mujer de la triste figura”. En Benito Pérez Galdós: Tristana. Barcelona, Austral: sp.

MAZzonI, Guido (2011): Teoria del romanzo. Bolonia, Il Mulino.

MoReTTI, Franco (1999): Il romanzo di formazione. Turín, Einaudi.

PÉREZ GALDÓs, Benito (2006): “Un tribunal literario". La princesa y el granuja. Relatos breves. Artemisa, Tenerife: 153-207.

PolizzI, Assunta (2019): "Galdós, el periodismo y la escritura. Reflexiones a partir del cuento «El artículo de fondo»". En Actas del XI Congreso Internacional de Estudios Galdosianos (2019): 201-217.

SAlado Álvarez, Victoriano (1920): “Galdós”. La Prensa VI/810, 25 de enero de 1920: 10.

--- (1924): "Sobre Rubén Darío". La Prensa XII/183, 13 de agosto de 1924: 3.

--- (2019): "De la vida de bohemia". Diálogos de otros tiempos. Narraciones y sucedidos mexicanos. Ed. Alejandro Sacbé Shuttera Pérez. México, Penguin: 43-48.

SÁNCHEZ RoBles, María Guadalupe (2021): "La movilidad como re-escritura identitaria en De Santa Anna a la Reforma, de Victoriano Salado Álvarez". En Alejandro Shuttera (coord.): Tiempo viejo (1867)-Tiempo nuevo (2017). Presencia(s) de Victoriano Salado Álvarez en el siglo XXI. México, Universidad Nacional Autónoma de México: 35-53.

Segre, Cesare (1985): Principios de análisis del texto literario. Barcelona, Crítica.

SHUTtERA, Alejandro (2018): "Estudio preliminar". En Victoriano Salado Álvarez: Episodios nacionales, I. De Santa Anna a la Reforma, 1. Su Alteza Serenísima. México, Universidad Nacional Autónoma de México: XVII-XLVIII.

Vital, Alberto (2002): Un porfirista de siempre. Victoriano Salado Álvarez, 1867-1931. México, Universidad Nacional Autónoma de México-Universidad Autónoma de Aguascalientes.

--- (2012): “Introducción”. En Victoriano Salado Álvarez: Narrativa breve. México, Universidad Nacional Autónoma de México: XIX-XCVII. 
--- (2021): "Cuatro géneros en la vida de Victoriano". En Alejandro Shuttera (coord.): Tiempo viejo (1867)—Tiempo nuevo (2017). Presencia(s) de Victoriano Salado Álvarez en el siglo XXI. México, Universidad Nacional Autónoma de México: 153-162.

ViVEROS, Luz América (2021): “«Traía del terruño tantos planes»: La incursión periodística de Victoriano Salado en la Ciudad de México". En Alejandro Shuttera (coord.): Tiempo viejo (1867)—Tiempo nuevo (2017). Presencia(s) de Victoriano Salado Álvarez en el siglo XXI. México, Universidad Nacional Autónoma de México: 163-182.

(C) Diego Mejía Estévez

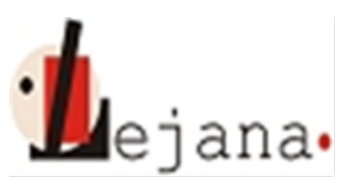

http://ojs.elte.hu/index.php/lejana

Universidad Eötvös Loránd, Departamento de Estudios Hispánicos

1088 Budapest, Múzeum krt. 4/C 